\title{
Special Issues in Honor of Professor Dr. Dr. hc mult. Wittko Francke, 28 November 1940 - 27 December 2020
}

\author{
Stefan Schulz ${ }^{1}$. Jocelyn G. Millar ${ }^{2}$ - Gary W. Felton ${ }^{3}$
}

Accepted: 12 November 2021 / Published online: 18 November 2021

(c) The Author(s), under exclusive licence to Springer Science+Business Media, LLC, part of Springer Nature 2021

The current issue is the first of two special issues honoring Professor Wittko Francke, one of the leading scientists in Chemical Ecology over the past 50 years. Prof. Francke died unexpectedly on 27 December 2020 at the age of 80 .

Wittko, as everybody called him, was an imaginative, rigorous, and competitive scientist and person, and a friend to many with a unique, energetic character. He turned his love for Chemistry, insects and Chemical Ecology into an extraordinary career. Even from his student days, he focused on Chemical Ecology, managing to convince his carbohydrate-oriented $\mathrm{PhD}$ advisor in Chemistry to let him work on volatile signals. His research focused on a structural perspective, the identification of semiochemicals, rooted in a comprehensive understanding of biosynthetic pathways of Natural Products and extending to the biological function of the target compounds. He published more than 350 original papers, making major contributions to Chemical Ecology as well as Organic Chemistry, elegantly combining organic trace analysis and synthesis, the latter a major part of his work. His ideas led to the identification of various new pheromone compound classes, such as his beloved spiroacetals, important as pheromones of bark beetles, flies, and Hymenoptera. Bark beetles were his special interest in the early part of his career and many studies on their pheromones were published, featuring compounds such as chalcogran or olean. During his career he expanded his interests into the pheromones of Lepidoptera, Hymenoptera, and numerous other types of beetles. Nevertheless, he was not focused solely on volatile pheromones, but made important contributions

Gary W. Felton

gwf10@psu.edu

1 Institute of Organic Chemistry, Technische Universitat Braunschweig, Braunschweig, Germany

2 Departments of Entomology and Chemistry, University of California, Riverside, CA 92521, USA

3 Department of Entomology, The Pennsylvania State University, University Park, PA 16802, USA to other fields such as chemical defenses (for example the huge alkaloid myrmicarin), unique bacterial volatiles such as sodorifen, water-borne signals, and compounds mediating insect-plant interactions. His approach was always characterized by close cooperation with biologists, thus establishing a dense global network of collaborators who often became friends, who were happy to benefit from his unique knowledge. On the other hand, Wittko had an excellent grounding in entomology, allowing him to understand and appreciate the nuances of chemically mediated behaviors in insects, and making him a much-sought after discussion partner for many projects. This interdisciplinary side is nicely illustrated by, among numerous other awards, the prestigious medals bestowed on him by two German scientific societies, the Society of German Chemists and the German Society for Applied and General Entomology, certifying his impact both in Chemistry and Entomology. Looking back on his work, it is clear that he brought structure elucidation of trace amounts of unknown chemical signals to a new level, introducing new strategies and methods for the identification and synthesis of volatile semiochemicals. Furthermore, he advocated the importance of biosynthesis in Chemical Ecology and was a strong promoter of behavioral experiments for establishing and verifying functions of putative semiochemicals, to provide the "smoking gun" evidence for their biological activities.

Part of the explanation for Professor Francke's extraordinary productivity may have been due to his apparent ability to get by with almost no sleep. He would work a full day at the University with his colleagues and students, and then continue to work on research and manuscripts until the early hours of the morning. It was not unusual for foreign colleagues in far different time zones to receive calls from him at 1 or 2 o'clock in the morning his time, still working and apparently full of energy. In a similar way, he was always ready to help others, particularly foreign colleagues with limited resources, and over the years he hosted numerous visiting scientists in his research group, helping them to 
jump-start their own careers once they returned home. He trained and mentored an extraordinary number and variety of "academic progeny", including distinguished professors in Germany and abroad, and scientists in industry.

In addition to these achievements, he was extremely active in University affairs, including teaching classes long after his official retirement, and serving numerous different roles within his department and university. He was also deeply rooted in his greater area home-town, Hamburg. Such energetic engagement, typical for him, was also visible in the promotion of younger scientists, in his group or elsewhere in the world. Of particular interest to him was the International Society of Chemical Ecology (ISCE), regarding it as the backbone of Chemical Ecology. The yearly meetings were essential to him, to exchange ideas, initiate new collaborations, and meet friends. Consequently, he served as president of the ISCE and in other roles, including hosting one of the largest and most successful of the Society's annual meetings. He even designed the logo of the society, and took charge of minting the Society's Silver and Copper Medals until his passing. Wittko also served as an Associate Editor of the Journal of Chemical Ecology, and a coeditor of Chemoecology, becoming a devotee in the truest sense. He brought to this work the same diligence, uncompromising insistence on scientific rigor, and enthusiasm that was characteristic of his other endeavors. His contributions in this regard were exemplary and monumental. It is fitting that these special issues acknowledge that.

This first of the two special issues honoring Professor Francke's memory reflects the breadth of his interests in chemical ecology, and the wide variety of collaborators and colleagues with whom he worked. The issue commences with a methodological paper from Hans Alborn's group (Alborn et al. 2021), comparing three different methods of collecting volatiles from living organisms (trapping on Tenax with thermal desorption, solid phase microextraction (SPME), and solid phase dynamic extraction (SPDE)), and the biases, advantages, and disadvantages of each method. Whereas it is generally known within the chemical ecology community that each method has its biases, it is useful to have a careful, qualitative, and quantitative study that systematically compares those biases. The second paper, by Weliton Silva and coauthors (Silva et al. 2021) describes the identification of pheromone components from several South American cerambycid beetle species. Some of the first work on cerambycid pheromones was done in Professor Francke's group in the 1990s, and one of the compounds that his group identified, 3-hydroxyhexan-2one, is continuing to be found in the pheromone blends of cerambycid beetles worldwide, including the species described in this study. The next contribution, from Christer Löfstedt's team (Xia et al. 2021) describes their continuing work aimed at addressing an ongoing problem in the practical application of semiochemicals, that is, the efficient and cost-effective production of the active components. They describe their experiments using genetically modified plants as "bioreactors" to produce codlemone, the major component of the pheromone of the codling moth, a global pest of pome fruit. The next manuscript from Paulo Zarbin's group (Bandeira et al. 2021), with Professor Francke as a coauthor, is a valuable and timely review of weevil pheromones. Among many other collaborations with Zarbin's group, Professor Francke worked directly on the identification of pheromones for several South American weevil species. The subsequent paper (Vuts et al. 2021) reflects Professor Francke's longterm collaboration with the Hungarian research team headed by Miklós Tóth and Gábor Szőcs, and now being continued by their academic progeny. This paper, examining responses of the dried bean weevil to host plant volatiles, builds on previous work in which Professor Francke helped the team to identify missing components of the dried bean weevil pheromone. The issue continues with a very interesting article from Monika Hilker's group (Awater-Salendo et al. 2021), which examined the characteristics of kairomonal trails deposited by larvae of the confused flour beetle, Tribolium confusum. The trails consist of cuticular hydrocarbons, which lose their attraction to host-seeking parasitoids after a couple of days due to changes in the physical structure of the deposited mixture of $\mathrm{CHCs}$, and not to changes in the trail's chemical composition. The activity could be restored by brief treatment with hexane, which broke up and remixed the solid filaments of CHCs which had formed. The next contribution from Andrés Gonzalez' group in Uruguay (de la Vega et al. 2021) examined differences in the profile of volatiles released by intact blueberry fruit and blueberries infested with larvae of the invasive spotted wing drosophila, Drosophila suzukii, and how those differences might affect the behavior of the endemic parasitic wasp Trichopria anestrephae, a potential biological control agent for the fruit fly. The team found that the wasp was innately attracted to the altered odor profile of the infested blueberries, despite the fact that the wasp has not coevolved with this particular potential host, holding out hope that the wasp could help to control infestations of the fruit fly. Rob Raguso, representing a large team of international collaborators including Professor Francke (Tröger et al. 2021) then summarizes the results of an investigation into the chemical ecology of one of the textbook examples of coevolution, between yucca plants and the yucca moths which pollinate them. Although the biological and ecological aspects of this system have been well studied, virtually nothing was known about the suite of volatiles that specifically 
attracted the pollinating species to their hosts. In a collaboration spanning two decades, Professor Francke played a crucial role in the identification and synthesis of the novel tetranorsesquiterpenoids that mediate these interactions, providing a first glimpse into the chemical ecology that underpins this obligate pollination mutualism system. Bill Hansson's group (Nataraj et al. 2021) then describe investigations of oviposition site choices of the hawk moth, Manduca sexta. Many pollinating insects learn and return to species of flowers from which they have previously fed, known as flower constancy. Here, the group showed that an analogous behavior exists for oviposition, with moths preferentially choosing to lay eggs on plant species on which they had previously oviposited. The issue concludes with a study from Anjel Helms' laboratory (Marmolejo et al. 2021), examining the herbivore-induced plant volatiles (HIPVs) induced by feeding of three different insect species (saltmarsh caterpillar, squash bug, and striped cucumber beetle) on zucchini plants. The group found that HIPVs induced by saltmarsh caterpillar feeding suppressed the defenses of nearby zucchini plants, resulting in greater damage when those plants were subsequently fed upon by saltmarsh caterpillars. In contrast, the HIPVs induced by squash bugs and striped cucumber beetles did not affect resistance and damage levels in nearby plants.

Overall, this group of manuscripts exemplifies the breadth and maturity of chemical ecology as a discipline, and the tremendous synergism between chemists and biologists in these cross-disciplinary studies. Professor Francke played a major role in the growth and development of chemical ecology, becoming the "go-to" chemist for numerous research groups around the world, as well as being a guiding force in the foundation of the International Society of Chemical Ecology and the Journal of Chemical Ecology. The second issue will continue this theme, with a planned publication date in early 2022.

\section{References}

Alborn HT, Bruton RG, Beck JJ (2021) Sampling of volatiles in closed systems: a controlled comparison of three solventless volatile collection methods. J Chem Ecol. https://doi.org/10.1007/ s10886-021-01306-6

Awater-Salendo S, Voigt D, Hilker M, Furstenau B (2021) Cuticular hydrocarbon trails released by host larvae lose their kairomonal activity for parasitoids by solidification. J Chem Ecol. https://doi. org/10.1007/s10886-021-01310-w

Bandeira PT, Fávaro CF, Francke W, Bergmann J, Zarbin PHG (2021) Aggregation pheromones of weevils (Coleoptera: Curculionidae): advances in the identification and potential uses in semiochemical-based pest management strategies. J Chem Ecol. https://doi. org/10.1007/s10886-021-01319-1

de la Vega GJ, Triñanes F, González A (2021) Effect of Drosophila suzukii on blueberry VOCs: chemical cues for a pupal parasitoid, Trichopria anastrephae. J Chem Ecol. https://doi.org/10.1007/ s10886-021-01294-7

Marmolejo L, Thompson M, Helms A (2021) Defense suppression through interplant communication depends on the attacking herbivore species. J Chem Ecol. https://doi.org/10.1007/ s10886-021-01314-6

Nataraj N, Adam E, Hansson BS, Knaden M (2021) Host plant constancy in ovipositing Manduca sexta. J Chem Ecol. https://doi.org/ 10.1007/s10886-021-01309-3

Silva WD, Hanks LM, Bento JMS, Millar JG (2021) 3-Hydroxyhexan2-one and 3-methylthiopropan-1-ol as pheromone candidates for the South American cerambycid beetles Stizocera phtisica and Chydarteres dimidiatus dimidiatus, and six related species. J Chem Ecol. https://doi.org/10.1007/s10886-021-01313-7

Tröger A, Svensson GP, Galbrecht HM, Twele R, Patt JM, Bartram S, Zarbin PHG, Segraves KA, Althoff DM, von Reuss S, Raguso R, Francke W (2021) Tetranorsesquiterpenoids as attractants of yucca moths to yucca flowers. J Chem Ecol. https://doi.org/10. 1007/s10886-021-01308-4

Vuts J, Szanyi S, Szanyi K, König L, Nagy A, Imrei Z, Birkett MA, Tóth M (2021) Development of a phytochemical-based lure for the dried bean beetle Acanthoscelides obtectus Say (Coleoptera: Chrysomelidae). J Chem Ecol. https://doi.org/10.1007/s10886-021-01305-7

Xia Y-H, Wang H-L, Ding B-J, Svensson GP, Jarl-Sunesson C, Cahoon EB, Hofvander P, Löfstedt C (2021) Green chemistry production of codlemone, the sex pheromone of the codling moth (Cydia pomonella), by metabolic engineering of the oilseed crop camelina (Camelina sativa). J Chem Ecol. https://doi.org/10.1007/ s10886-021-01316-4 